\title{
On-and-off deployment technique of a lumen-apposing metal stent during endoscopic pancreatic necrosectomy
}

Endoscopic ultrasound-guided transmural drainage (EUS-TMD) with lumenapposing metal stent (LAMS) and endoscopic necrosectomy are widely recognized as effective treatments for walledoff pancreatic necrosis (WON) [1-3]. However, in particular situations, the LAMS becomes an unexpected encumbrance to endoscopic necrosectomy. Moreover, necrosectomy devices sometimes catch the LAMS incidentally, which might result in LAMS migration.

A 35-year-old man underwent EUS-TMD with a $15 \times 10 \mathrm{~mm}$ LAMS (AXIOS; Boston Scientific, Marlborough, Massachusetts, USA) for lateral widespread and irregular-shaped WON caused by necrotizing pancreatitis ( $\mathbf{F i g . 1}$ ). On initial necrosectomy, the distal end of the LAMS was clogged by the opposite wall, and WON access was tightly obstructed, resulting in failure of endoscopic trans-LAMS advancement to the cavity ( $\triangleright$ Fig. 2 ). To open the route, the LAMS was first removed with a snare, and necrosectomy was performed using 5-prong forceps to grab the larger necrotic tissues. After the session, the LAMS was redeployed with a novel technique to prevent the fistula from closing. Using a 15-mm snare, the distal flange of the LAMS was grasped through the channel of a twochannel gastroscope. The LAMS was then squeezed to load backward into the other channel of the endoscope. The distal flange grasped by the snare was inserted into the WON by cooperative advancement of the snare and a pusher catheter. After full deployment of the proximal flange in the gastric lumen, the grasping snare released the distal flange to complete LAMS redeployment ( $>$ Fig. $\mathbf{3}$, - Video 1). This "on-and-off" procedure was performed six times in total until endoscopic necrosectomy was accomplished, without any complications.

Temporary removal and redeployment of LAMS during endoscopic necrosectomy offers advantages, both to create a space
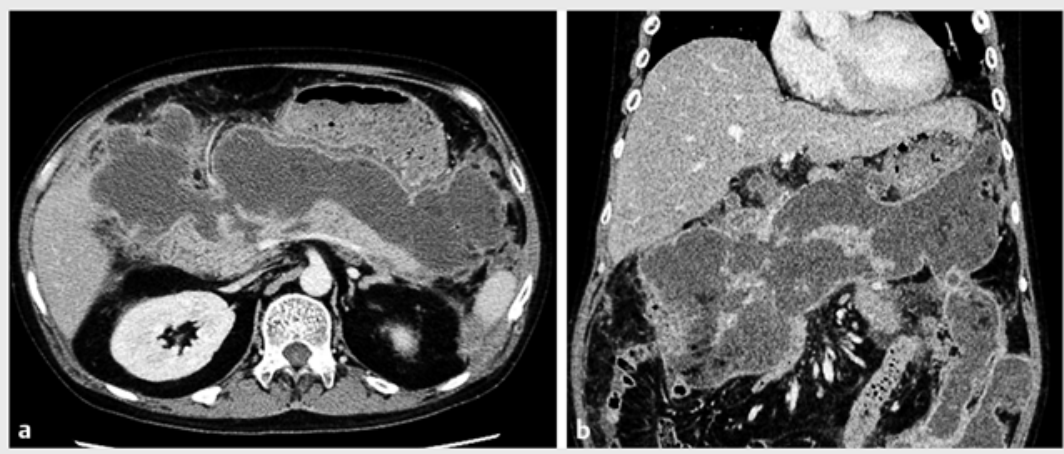

- Fig. 1 Contrast-enhanced computed tomography views. a, b Widespread and irregularshaped wall-off necrosis caused by necrotizing pancreatitis.
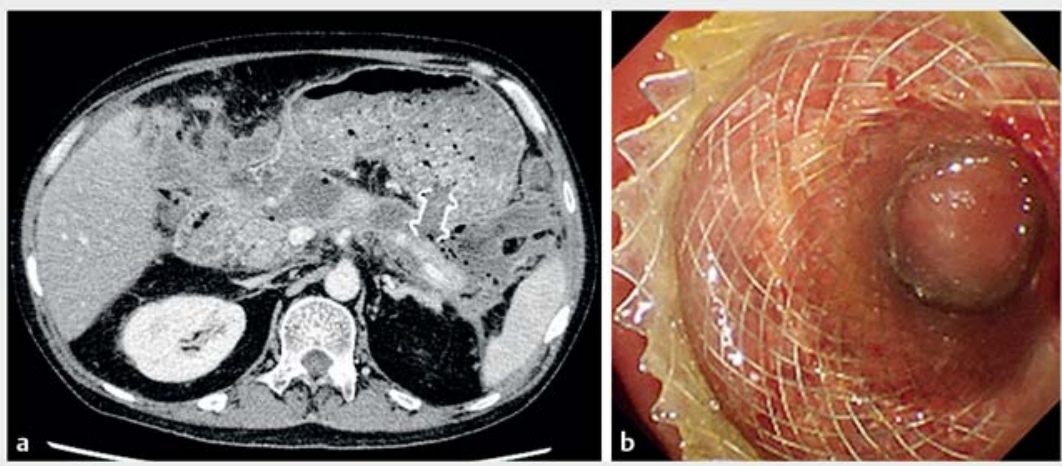

Fig. 2 Lumen-apposing metal stent (LAMS) views. a Contrast-enhanced computed tomography view showing that, after successful endoscopic ultrasound-guided transgastric drainage, the wall-off necrosis (WON) had partially shrunk, but the distal end of the LAMS was clogged by the opposite wall of the transmural site. $\mathbf{b}$ Endoscopic image showing the distal end of the LAMS, which was obstructed and clogged, with no route to the WON cavity.

without flange disturbance to insert the endoscope into a burdensome WON, and to obtain larger necrotic tissues by higher grip force devices without interference with the LAMS.

Endoscopy_UCTN_Code_TTT_1AS_2AC

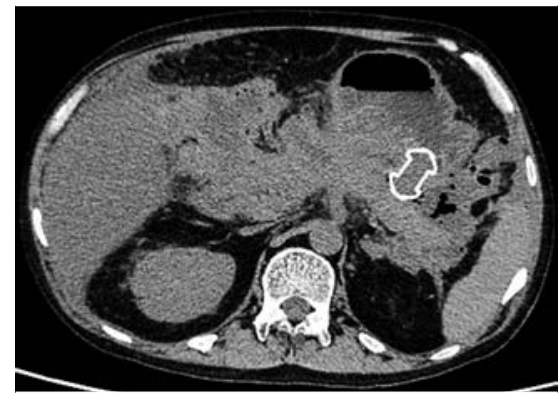

Competing interests

None
- Fig. 3 Computed tomography view showing the LAMS sitting in the appropriate position after repetitive temporary removal and redeployment. 


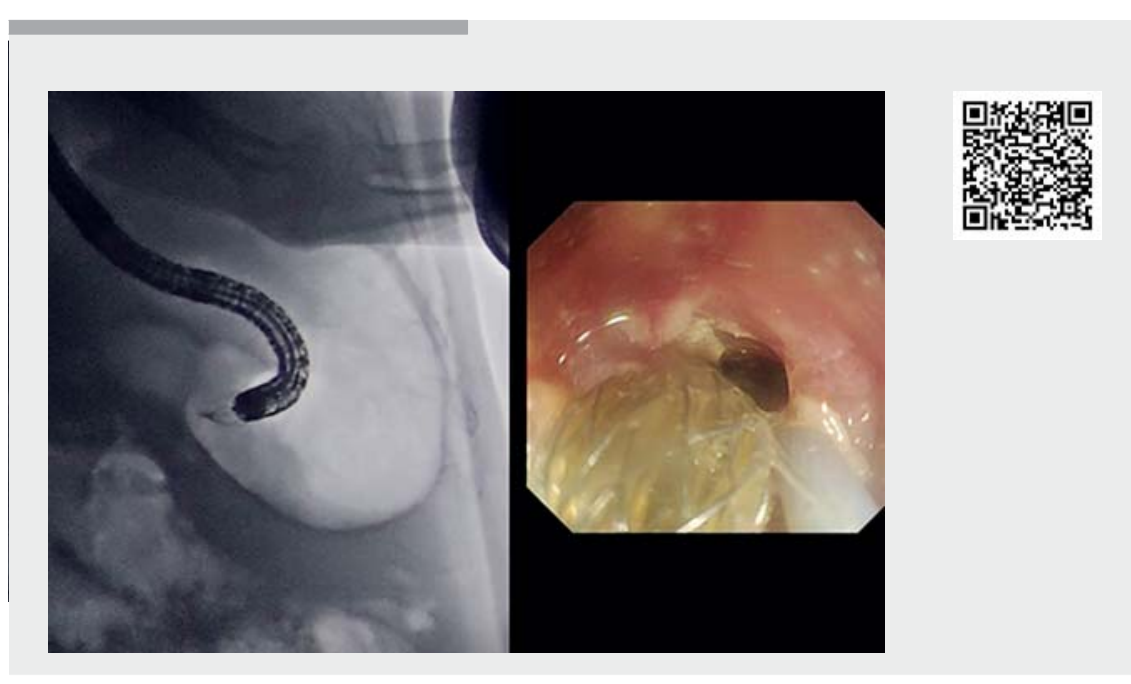

$\checkmark$ Video 1 Novel technique of "on-and-off deployment" of a lumen-apposing metal stent for effective endoscopic pancreatic necrosectomy.
The authors

\section{Michihiro Yoshida, Itaru Naitoh, Ruriko} Yamada, Kazuki Hayashi, Makoto Natsume, Yasuki Hori, Hiromi Kataoka

Department of Gastroenterology and Metabolism, Nagoya City University Graduate School of Medical Sciences, Nagoya, Japan

\section{Corresponding author}

\section{Itaru Naitoh, MD}

Department of Gastroenterology and Metabolism, Nagoya City University Graduate School of Medical Sciences, 1 Kawasumi, Mizuho-cho, Mizuho-ku Nagoya 467-8601, Japan Fax: +81-52-852-0952

inaito@med.nagoya-cu.ac.jp
[1] Yip HC, Teoh AYB. Endoscopic management of peri-pancreatic fluid collections. Gut Liver 2017; 11: 604-611

[2] Walter D, Will U, Sanchez-Yague A et al. A novel lumen-apposing metal stent for endoscopic ultrasound-guided drainage of pancreatic fluid collections: a prospective cohort study. Endoscopy 2015; 47: 63-67

[3] Galasso D, Baron TH, Attili F et al. Endoscopic ultrasound-guided drainage and necrosectomy of walled-off pancreatic necrosis using a metal stent with an electrocautery-enhanced delivery system and hydrogen peroxide. Endoscopy 2015; 47 (Suppl. 01): E68

\section{Bibliography}

DOI https://doi.org/10.1055/a-1046-1513

Published online: 2.12.2019

Endoscopy 2020; 52: E158-E159

(c) Georg Thieme Verlag KG

Stuttgart · New York

ISSN 0013-726X

\section{ENDOSCOPY E-VIDEOS}

https://eref.thieme.de/e-videos

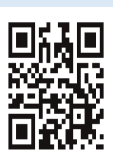

Endoscopy E-Videos is a free access online section, reporting techniques in gastroenterological endoscopy. All papers include a high quality video and all contributions are freely accessible online.

This section has its own submission website at https://mc.manuscriptcentral.com/e-videos 